\title{
Editorial
}

\section{Digital-A New Open Access Journal to Report on Recent IT Advancements and Their Implementations for Interdisciplinary Research}

\author{
Yannis Manolopoulos
}

check for

updates

Citation: Manolopoulos, Y.

Digital-A New Open Access Journal

to Report on Recent IT

Advancements and Their

Implementations for Interdisciplinary

Research. Digital 2021, 1, 64-65.

https://doi.org/10.3390/digital1010005

Received: 24 February 2021

Accepted: 26 February 2021

Published: 28 February 2021

Publisher's Note: MDPI stays neutral with regard to jurisdictional claims in published maps and institutional affiliations.

Copyright: (C) 2021 by the author. Licensee MDPI, Basel, Switzerland. This article is an open access article distributed under the terms and conditions of the Creative Commons Attribution (CC BY) license (https:/ / creativecommons.org/licenses/by/ $4.0 /)$.
Faculty of Pure and Applied Sciences, Open University of Cyprus, 2220 Nicosia, Cyprus; yannis.manolopoulos@ouc.ac.cy

Many decades back, Computer Science emerged as a new scientific discipline at the crossroads of mathematics, physics and engineering. For a long period, Computer Science's syllabuses and computing curricula were static. However, after the invention of the World Wide Web, for the last two decades, new areas have emerged and expanded to such an extent that the terms describing the "next big things", such as "Web Science", "Internet Science", "Data Science", "Network Science" or "e-Science", audaciously tossed at first, gained increasing popularity [1]. Next to these, new key terms came to stay, such as quantum computing, optical computing, wearable computing, blockchain, analytics, sensor networks, cloud and software as a service, and many others. Jim Gray-a Turing awardee pioneer computer scientist, lost at sea in 2007-declared just before his disappearance the area of data-intensive computing and the fourth paradigm [2]. We are experiencing a DIGITAL revolution. Has the Pandora's box been opened [3]?

Along with the rather purely theoretical scientific advances, technological advances in materials—such as solid-state electronics, magnetic materials, or fiber optics-made possible the widespread use of the above in a plethora of other scientific disciplines, of interdisciplinary intersections and in everyday life, at home, at school, in amusement, in tourism, the list goes on. It was in 1980 that Alvin Toffler in his futuristic book entitled "The Third Wave" envisaged a number of technologies, such as personal computers, the internet, and mobile communication [4]. Nowadays, not only have these visionary predictions come true and are commodities, but irreversible consequences appeared in economy, government and all social sectors.

We have thus entered the era of the fourth paradigm [5], the first three being (a) the experimental or empirical evidence, (b) the scientific theory, and (c) the computational science. In simple words, the tremendous increase in storage capacities, microprocessor speeds, and network throughputs along with the dramatic decrease in their costs produced an unforeseeable overwhelming flow of data, which now demands a change of the computing milieu. The fourth paradigm introduces Data Science and leads to the popular term of Big Data [6]. The only way to cope with the "exaflood" of observational data is a new generation of scientific computing tools to store, process, visualize and analyze the deluge of data [7]. Jim Gray suggested that things should move to "a world in which all of the science literature is online, all of the science data is online, and they interoperate with each other" [8]. He applied his vision to the field of astronomy, and before that to global geographic information systems with the Sequoia project and worked with others to show how to apply the approach to fields such as molecular biology, sensor networks for environmental science, and oceanography, as mentioned during the ceremony where he received the Turing award [9].

So, the Fourth Paradigm goes hand in hand with the Fourth Industrial Revolution (Industry 4.0), which refers to automation of traditional manufacturing and industrial practices, using modern smart technologies. Distributed processing systems and the internet of things (IoT) have changed the landscape of human labor, amusement and 
leisure, practically all human activities, including education (Education 4.0). This is where Digital comes in and provides room for publishing research outcomes.

Digital is open to receive contributions that advance the computing field in core areas such as distributed systems, blockchain technologies, data analytics, social network analysis—even at web scale-serious games, multimedia processing. Moreover Digital, as a multidisciplinary forum, encourages scientists to submit contributions in other fields where (big) data play a crucial role. To name just a few, we mention medical and health sciences, biotechnology, nanotechnology, digital humanities, digital economy including fintech approaches, agricultural sciences, educational analytics, digital ecosystems such as smart cities and buildings, digital marketing and commerce. The list is by no means exhaustive: in fact, the list is practically extremely long as the world is moving to a DIGITAL era, the Age of Algorithms [10].

Conflicts of Interest: The author declares no conflict of interest.

\section{References}

1. Tiropanis, T.; Hall, W.; Crowcroft, J.; Contractor, N.; Tassiulas, L. Network Science, Web Science, and Internet Science. Commun. ACM 2015, 58, 76-82. [CrossRef]

2. Gray, J. Talk to the NRC-CSTB in Mountain View. Available online: http://research.microsoft.com/en-us/um/people/gray/ JimGrayTalks.htm (accessed on 1 February 2021).

3. Heldbing, D. Thinking Ahead-Essays on Big Data, Digital Revolution, and Participatory Market Society; Springer: Cham, Switzerland, 2015.

4. Toffler, A. The Third Wave; Bantam Books: New York, NY, USA, 1980.

5. Hey, T.; Tansley, S.; Tolle, K. The Fourth Paradigm—Data-Intensive Scientific Discovery; Microsoft Research: Redmond, WA, USA, 2009. Available online: https://www.microsoft.com/en-us/research/wp-content/uploads/2009/10/Fourth_Paradigm.pdf (accessed on 1 February 2021).

6. Glinos, K. E-infrastructures for Big data: Opportunities and Challenges. ERCIM News, 4 April 2012; p. 2.

7. Tolle, K.M.; Tansley, D.S.W.; Hey, A.J.G. The Fourth Paradigm: Data-Intensive Scientific Discovery [Point of View]. Proc. IEEE 2011, 99, 1334-1337. [CrossRef]

8. Markoff, J. A Deluge of Data Shapes a New Era in Computing. New York Times, 15 December 2009; p. 2. Available online: https://www.nytimes.com/2009/12/15/science/15books.html(accessed on 1 February 2021).

9. McJones, P. Introductory speech during Jim Gray's ACM Allan Turing Award. Available online: https://amturing.acm.org/ award_winners/gray_3649936.cfm (accessed on 1 February 2021).

10. Abiteboul, S.; Dowek, G. The Age of Algorithms; Cambridge University Press: Cambridge, UK, 2020.

\section{Short Bio of Yannis Manolopoulos}

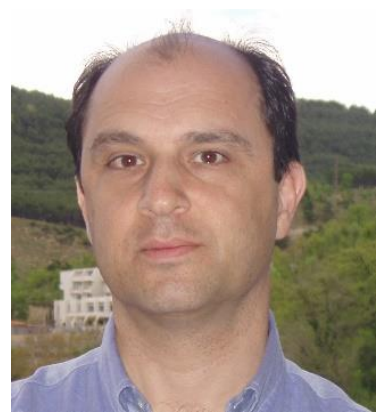

Yannis Manolopoulos is Professor and Vice-Rector of the Open University of Cyprus, Professor Emeritus of the Aristotle University of Thessaloniki, Member of the Board of the Research and Innovation Foundation of Cyprus. He has served as President of the University of Western Macedonia in Greece and Vice-President of the Greek Computer Society. His research interest focuses in Data Management $(h=56)$. 